\title{
Successional convergence in experimentally disturbed intertidal communities
}

Martins, Gustavo M.; Arenas, Francisco; Tuya, Fernando ; Ramirez, Ruben ; Neto, Ana Isabel; Jenkins, Stuart

\section{Oecologia}

DOI:

$10.1007 / \mathrm{s} 00442-017-4022-1$

Published: 01/02/2018

Peer reviewed version

Cyswllt i'r cyhoeddiad / Link to publication

Dyfyniad o'r fersiwn a gyhoeddwyd / Citation for published version (APA):

Martins, G. M., Arenas, F., Tuya, F., Ramirez, R., Neto, A. I., \& Jenkins, S. (2018). Successional convergence in experimentally disturbed intertidal communities. Oecologia, 186(2), 507-516. https://doi.org/10.1007/s00442-017-4022-1

\footnotetext{
Hawliau Cyffredinol / General rights

Copyright and moral rights for the publications made accessible in the public portal are retained by the authors and/or other copyright owners and it is a condition of accessing publications that users recognise and abide by the legal requirements associated with these rights.

- Users may download and print one copy of any publication from the public portal for the purpose of private study or research.

- You may not further distribute the material or use it for any profit-making activity or commercial gain

- You may freely distribute the URL identifying the publication in the public portal?
}

Take down policy

If you believe that this document breaches copyright please contact us providing details, and we will remove access to the work immediately and investigate your claim. 


\section{Successional convergence in experimentally disturbed intertidal communities}

Gustavo M. Martins ${ }^{1,2^{*}}$, Francisco Arenas ${ }^{3}$, Fernando Tuya ${ }^{4}$, Rubén Ramírez ${ }^{4}$, Ana I. Neto $^{1,2}$, Stuart R. Jenkins ${ }^{5}$

61 Faculdade de Ciências e Tecnologia, Departamento de Biologia, Universidade dos Açores, 9501-801 Ponta Delgada, Açores, Portugal.

82 cE3c - Centre for Ecology, Evolution and Environmental Changes/Azorean Biodiversity Group, 9501-801 Ponta Delgada, Açores, Portugal.

103 Interdisciplinary Centre of Marine and Environmental Research (CIIMAR) University of Porto, Terminal de Cruzeiros do Porto de Leixões

12 Av. General Norton de Matos s/n 4450-208 Matosinhos, Portugal.

4 Grupo en Biodiversidad y Conservación, IU-ECOAQUA, Universidad de Las Palmas de

14 Gran Canaria, Las Palmas, 35017, Canary Islands, Spain.

5 School of Ocean Sciences, Bangor University, Menai Bridge, Anglesey, UK.

16

* Corresponding author:

18 Email: gustavo.om.martins@uac.pt

Tel: +351296650101

20 Fax: +351296650100

\section{Author contributions:}

GMM, FA and SRJ conceived and designed the experiment. GMM, FA, FT, RR and AIN

24 performed the experiment. GMM analysed the data and wrote the manuscript with contribution from FA, FT, RR, AIN and SRJ. 


\section{ABSTRACT.}

Determining the causes of variation in community assembly is a central question in ecology. Analysis of $\beta$-diversity can provide insight by relating the extent of regional to local variation in diversity, allowing inference of the relative importance of deterministic versus stochastic processes. We investigated the effects of disturbance timing on community assembly at three distinct regions with varying environmental conditions: Northern Portugal, Azores and Canaries. On the lower rocky intertidal, quadrats were experimentally cleared of biota at three distinct times of the year and

34 community assembly followed for one year. Similar levels of $\alpha$ - and $\gamma$-diversity were found in all regions, which remained constant throughout succession. When Jaccard 36 (incidence-based) and Bray-Curtis (abundance-based) metrics were used, $\beta$-diversity (the mean dissimilarity among plots cleared at the different times) was larger during early stages of community assembly, but decreased over time. The adaptation of the Raup Crick's metric, which accounts for changes in species richness, showed that the structure of assemblages disturbed at different times of the year was similar to the null model of random community assembly during early stages of succession, but became more similar than expected by chance. This pattern was observed in all regions despite differences in the regional species pool, suggesting that priority effects are likely weak and deterministic processes determine community structure despite stochasticity during early stages of community assembly.

Keywords: Diversity; $\beta$-diversity; Deterministic; Stochastic; Community assembly; 


\section{INTRODUCTION}

52 The extent to which the structure of natural communities is determined by stochastic or deterministic processes is a central question in ecology. There has been strong debate

54 regarding the relative importance of niche-based, deterministic, processes and neutral stochastic processes for community assembly (Hubbell 2001; Wooton 2005; Alonso et

56 al. 2006; Dornela et al. 2006). Attempts to reconcile niche and neutral perspectives argue that they act as two ends of a continuum between competitive exclusion and stochastic immigration (Gravel et al. 2006), where both niche and neutral processes simultaneously influence the dynamics of competing species (Adler et al. 2007). It has also been shown that the relative importance of niche versus neutral processes can be scale-dependent, with the former becoming relatively more important at increasing spatial scales (Garzon-Lopez et al. 2014; Chase 2014), as well as changing with the level of resources (e.g. productivity) (Chase 2010).

64

Processes operating at different spatial scales interact to produce patterns of species distribution (e.g. Navarrete et al. 2005). In this context, measures of $\beta$-diversity, i.e. the variation in identities of species among sites or times (Anderson et al. 2011), provide a

68 link between scales, by relating the extent of regional and local variation in diversity (Whittaker 1960,1972). $\beta$-diversity can be a useful metric to understand patterns of species diversity across space and time, which can be driven by environmental conditions (e.g. Ellingsen and Gray 2002; Anderson et al. 2013), biological interactions

72 (e.g. Chase et al. 2009; Smith et al. 2009) and disturbance regimes (e.g. Chase 2007). Even though the study of $\beta$-diversity per se cannot be used to infer the mechanisms

74 determining community structure, it can be used to infer the importance of stochastic 
(see Chase and Myers 2011 and references therein) and/or neutral (Tucker et al. 2016)

76 processes, relative to niche-based processes for community assembly.

78 Marine ecosystems are generally regarded as open, since most animals and plants have complex life-cycles, including an initial planktonic dispersing stage. The arrival of new

80 individuals to adult habitats varies greatly both in space and time and is often independent of local adult abundances (Jenkins et al. 2009). In rocky intertidal ecosystems, early colonists of disturbed substrata tend to be opportunistic and fastgrowing species that are available for colonisation throughout the year and generally

84 include biofilms, foliose and filamentous algae belonging to genera such as Ulva, Polysiphonia, Ceramium, Ectocarpus (Jenkins and Martins 2010). Ulva spp. release spores all year around and have high dispersal abilities (Norton 1992), so that when space is freed, they are generally able to colonise. In contrast, late colonists tend to be more competitive perennial algae with more complex morphologies, as well as common invertebrates, such as barnacles and mussels. Many of these taxa have distinct reproductive periods, with propagules or larvae available in the water column only for short periods of time (Jenkins and Martins 2010). As a consequence, the timing of

92 disturbance has a large impact on patterns of species recruitment, because of seasonality in organisms' reproductive patterns (Dayton et al. 1984; Breitburg 1985;

94 Sousa 1985; Benedetti-Cecchi and Cinelli 1993; Jenkins et al. 2005; Underwood and Chapman 2006; Martins et al. 2010). This, in turn, may have long-lasting effects if the 96 distribution and composition of communities is strongly dependent on events occurring early in succession (Berlow 1997; Petraitis and Latham 1999). For instance, Benedetti-

98 Cecchi (2000) showed that littoral rockpools could be dominated by either canopy- or turf-forming algae depending on the timing of disturbance. Canopy algae were the 
dominant species in rockpools when the timing of disturbance matched their peak of recruitment, thus highlighting the importance of priority effects. In other cases,

102 however, post-settlement processes can completely erase the signal of dispersal or settlement and the structure of different adult assemblages, which vary in initial composition, converges (Caro et al. 2010).

106 Here, we investigated, through analysis of the successional patterns following disturbance at different times of the year, the relative strength of stochasticity for the assemblage of rocky shore assemblages at three distinct regions of the Atlantic. By stochastic processes we refer to the probability of propagule arrival at a given location

110 or time, temporal variation in growth rates, etc. Note that although the underlying mechanisms determining the numbers of propagules available in the water column, at a

112 given time and space, can be deterministic (e.g. seasonality in species reproduction), patterns of recruitment and mortality of post-settlement stages of marine organisms

114 are often stochastic (e.g. Vadas et al. 1992, Underwood and Chapman 2006). They reflect the interaction between multiple factors (e.g. variability in density of

116 reproductive adults, variable patterns of currents, spatial variability in predators, smallscale variability in environmental conditions), making predictions about patterns of

118 colonisation complex and virtually impossible (see Vellend et al. 2014, for further discussion of the point). In contrast, deterministic processes refer to those processes 120 that reduce variability by exploiting and maximising niche differences among species (e.g. environmental filters, biotic interactions). Our prediction is that stochastic

122 processes will be more important during early successional stages, reflecting variation in the match between the time resources (e.g. space) were made available (via 124 experimental disturbances done at different times of the year) and variability in 
demographics of early colonisers. This will be depicted by significant variation in $\beta$ -

126 diversity (temporal dissimilarity) among assemblages disturbed at different times of the year. It should also be depicted by a similar pattern between the structure of these

128 assemblages and those created by a null model of random community assembly. As succession proceeds, however, we hypothesise that niche-based processes (e.g.

130 competition, environmental filtering) favouring the establishment of certain species will tend to lead to a deterministic signal, with the outcome of succession being invariant

132 regardless of variability (or stochasticity) in early stages of community assembly. This will be detected by a reduction in $\beta$-diversity (temporal dissimilarity) with time among

134 assemblages disturbed at different times of the year and divergence from the null model of random community assembly.

If niche-based processes prevail at later stages of community assembly, we can also

138 investigate the role of historical contingency (priority effects) in determining community structure. Priority effects (or divergent selection) can be assessed by

140 showing whether the variability generated during early successional stages of community assembly disturbed at different times of the year can lead to

142 later-successional assemblages that are clearly distinct (preserving the stochastic signal) and are more diverse than expected by chance. In contrast, if priority effects are

144 not important, biological interactions and environmental filtering will lead to a convergent selection resulting in assemblages that are less diverse than expected by 146 chance.

\section{MATERIAL AND METHODS}

\section{Study sites}


150 The study was done on the lower shore, algal-dominated, rocky intertidal at three locations in each of three regions: Northern Portugal, the Azores and the Canary Islands.

152 These three regions are all part of the Lusitanian province, but differ in latitude by 14 degrees. Northern Portugal is a cold-temperate zone at the transition between the

154 Atlantic and Mediterranean biogeographical regions (Lima et al. 2007; Tuya et al. 2012) and supports a highly diverse biota where many cold- and warm-water species have

156 their latitudinal limits of distribution (Araújo et al. 2009 and references therein). The Azores are located at the transition between the temperate and subtropical regions,

158 whereas the Canary Islands are located well within the subtropical region. The Northern Portugal and the Canary Islands are influenced by the Canary Upwelling

160 System (Iberian system), one of the major upwelling regions in the world (see Santos et al. 2011 and references therein). The Canary Islands and the Azores are oceanic

162 archipelagos belonging to the Macaronesia region. The two archipelagos differ in that the Canary Islands are considered a hotspot for biodiversity, whereas the Azores

164 support a comparatively less diverse biota due to the high degree of isolation and recent geological age (Hawkins et al. 2000; Tuya and Haroun 2009). Unlike the adjacent

166 continental mass, oligotrophic oceanic waters (Martins et al. 2007) generally surround the Canary Islands and the Azores, although productivity can be occasionally high due to island effects (see Hernández-Léon 1988), especially in the Canary Islands (see Table 1 in Martins et al. 2014 for environmental differences among these regions).

\section{Study communities}

172 In Northern Portugal, the lower shore was a patchy mosaic of algae dominated by coarsely branched algae (e.g. Osmundea spp., Dictyota spp.) or the leathery alga

174 Bifurcaria bifurcata. The Azores and Canaries were dominated by articulated corallines 
(e.g. Ellisolandia elongata, Jania rubens) and algal turfs consisting of coarsely branched

176 and filamentous (e.g. Palisada perforata, Chaetomorpha spp.) algae. At this shore level, animals present included Mytilus sp. and Sabellaria alveolata (only in Northern

178 Portugal), chthamalid barnacles, gastropod molluscs (patellid limpets, trochid snails and muricid whelks) and sea urchins (Paracentrotus lividus). Animals were, however,

180 generally rare in our study sites at the chosen shore level.

\section{Sampling design}

At each location, a total of thirty $15 \times 15 \mathrm{~cm}$ plots were haphazardly established on the

184 lower algal-dominated shore in areas of gentle sloping, well-drained, bedrock. Plots were marked with stainless steel screws and plastic tags. Plots were then randomly assigned to two treatments: disturbed (15 plots) and control (15 plots). Disturbed plots were cleared of biota by chiselling and scrubbing off all visible biota and blow-torched afterwards. The size of disturbed plots $\left(225 \mathrm{~cm}^{2}\right)$ is within the range of sizes of naturally disturbed patches observed in the rocky intertidal both in the Azores (Martins et al. 2013) and elsewhere (Airoldi 2003). Control plots were left un-manipulated and are used as a surrogate for mature communities. To test the influence of disturbance

192 timing, clearance of biota was carried out at three distinct times of the year (April, July and October of 2011). Five plots (of the 15 assigned to the disturbance treatment) were

194 randomly assigned to each time. Disturbed plots were then visually inspected at one, three, six, nine and twelve months after disturbances. A different set of unmanipulated 196 control plots $(n=5)$, out of those initially marked $(n=15)$, was also sampled when each set of disturbed plots reached 12 months (April, July and October of 2012).

198 Algae and sessile animals were quantified using the method described by Dethier et al. (1993), where a score of 0-4 (0 being absence, 4 being full cover) was given to each 
taxon in each of the 25 subdivisions making up the sampling quadrat $(15 \times 15 \mathrm{~cm})$. Rare species were marked as present and ascribed an arbitrary cover of $1 \%$. Mobile animals

202 (e.g. limpets) were counted as density of individuals. However, these were rare in our dataset and were not further considered in the analyses. All species were identified in

204 situ to the lowest taxonomic resolution possible. Where in doubt, sample specimens were collected nearby and brought to the laboratory for latter identification.

\section{Data analysis}

208 We examined the effect of timing of disturbance on the structure of assemblages through succession (i.e. 1 month, 3 months, etc., following disturbance) among regions 210 using a four-way PERMANOVA (Anderson 2001) with the factors: Region (random, 3 levels), Timing of Clearance (random, 3 levels), Location (random and nested within

212 region, 3 levels) and Successional Month (fixed, 6 levels). The analysis was run using Bray-Curtis dissimilarities on the fourth-root transformed data. Canonical Analysis of

214 Principal Coordinates (CAP) was used to ordinate samples in a bidimensional space, but constrained by the interaction between time of clearance and successional month. For

216 clarity, the data plotted are the centroids for each location. All analyses were done using PRIMER v6 + PERMANOVA add-on, Anderson 2001, Clarke and Gorley 2006).

For each location, $\alpha$-diversity of macrobiota was calculated as the average number of species pooled across the three disturbance timings $(n=15$ per location) and $\gamma$ diversity as the total number of species.

To place these results in a global perspective, we investigated whether regional enrichment of local diversity varied with succession. This was addressed by using the 
$\log$-response ratio effect size of regional-to-local diversity $[\ln (\gamma$-diversity $) / \ln (\alpha$ -

226 diversity)]. The use of the ratio enabled us to measure the extent of regional pool influence on local diversity without any unknown bias stemming from inaccurately estimating regional species pool among regions and at different successional stages. Spatial and temporal variation in the response ratio was investigated using a 2-way

230 permutational ANOVA with the factors: Region (random) and Successional Month (fixed). The analysis was run using Euclidean dissimilarities on PRIMER v6 +

232 PERMANOVA add-on. When based on Euclidean distance, PERMANOVA is analogous to traditional ANOVA, while maintaining the flexibility and lack of assumptions of other 234 non-parametric methods (Anderson 2001). in parametric assumptions. Prior to analysis, PERMIDSP was used to test for heterogeneity of variances and transformations were applied if necessary.

238 We then estimated $\beta$-diversity as the mean dissimilarity in the structure of assemblages disturbed at different times of the year using three metrics. Hence, in our study, $\beta$ -

240 diversity is a measure of temporal dissimilarity. We used the Jaccard's incidence-based dissimilarity metric to estimate temporal $\beta$-diversity (among disturbance timings) and

242 the Bray-Curtis dissimilarity index to include an abundance-based metric. However, because most similarity (or dissimilarity) metrics are confounded by variation in local

244 species richness, we further used the approach described by Chase et al. (2011), which is an adaptation of the Raup and Crick's metric. This estimates the probability of the number of co-occurring species with species occurrences probabilities proportional to species frequencies (Raup and Crick 1979). It estimates the probability that, in our case, 248 time-to-time dissimilarity ( $\beta$-diversity) is due to chance (Chase et al. 2011). This metric is then used to determine the relative strength of stochastic versus deterministic 
250 processes for community assembly (Chase 2010; Chase and Myers 2011; Chase et al. 2011; Stegen et al. 2012). The metric is standardised between -1 and 1 , where -1

252 indicates that communities are more similar than expected by chance, 1 indicates communities are more dissimilar than expected by chance, and 0 indicates communities

254 that do not differ from random expectation. The Jaccard and Bray-Curtis dissimilarities were calculated using PRIMER v6. For the Raup-Crick, we used the code provided in

256 Chase et al. (2011) to perform all the analyses. For each of the above three metrics, $\beta$ diversity was calculated as the mean dissimilarity between disturbance timings by

258 averaging all the possible combinations among quadrats disturbed at different times of the year, separately for each location and successional stage $(n=75)$. For controls, we

260 similarly calculated the mean dissimilarity between different sampling times by averaging all the possible combinations among undisturbed quadrats sampled at

262 different times of the year. This yielded a total of three values per region and successional stage, which were used to test variation in the effect of disturbance timing

264 at different successional stages and among regions using a 2-way permutational ANOVA (as described above). In our study, $\beta$-diversity is thus a measure of temporal

266 dissimilarity among quadrats disturbed (or sampled in the case of controls) at different times of year, calculated separately for each location and plot age. Note also that, as for

268 the estimates of $\alpha$ - and $\gamma$-diversity, $\beta$-diversity metrics were calculated separately for each successional stage; the rationale being that only a subset species of the regional species pool can de facto colonise disturbed patches at any given time (early vs. late successional species).

We have then used the approach of Hillebrand et al. (in press) to investigate the relative 274 importance of changes in species composition (SER $)$ and abundances (SERa) for 
assemblage turnover through succession. SER $\mathrm{r}$ and SER $\mathrm{R}_{\mathrm{a}}$ were calculated for each

276 quadrat at successive sampling times. Spatial and temporal variation in $\mathrm{SER}_{\mathrm{r}}$ and SERa was then analysed separately using a 4-way permutational ANOVA as described above.

\section{RESULTS}

280 For the overall study, we found a total of 115 species; 58 in Northern Portugal, 52 in the Canary Islands and 48 in the Azores. Of these, 36 species were exclusive to Northern

282 Portugal, 26 to the Canary Islands and 20 to the Azores; 33 species were present in at least two regions, whilst only 10 species were shared among all regions. Assemblage

284 structure varied significantly with Time of Clearance (TC) and Successional Month (SM) at both regional spatial scales $(\mathrm{P}=0.001$ for Region $\mathrm{x}$ TC $\mathrm{x}$ SM interaction $)$ and local spatial scales $(\mathrm{P}=0.001$ for Location nested in Region x TC x SM interaction, see Online Resource 1). Inspection of pair-wise comparisons (see also Online Resource 1) showed 288 that Time of Clearance had a significant $(\mathrm{P}<0.05)$ effect on the structure of assemblages, especially during early stages of community succession. The duration of

290 these effects (how long into the successional stage they were apparent) appears to have decreased with latitude, lasting longer in Northern Portugal (effects of timing of

292 clearance were detected up to 9 months after clearance) and less in the Canary Islands (effects of timing of clearance could not be detected 3 months after clearance) (Fig. 1).

294 Although the Time of Clearance had a significant effect on early assemblage structure, such effects were entirely absent ( $\mathrm{P}>0.05$ in all cases) for all regions 12 months after

296 disturbance (Fig. 1, see Online Resource 1). The largest source of variability was associated with the factor Regions (39\%, see coefficients of variation in Online Resource 298 1), highlighting the substantial variation in assemblage structure among these. 
300 The log-response ratio effect size of regional-to-local diversity did not differ significantly among regions or throughout succession (Fig. 2; see Online Resource 2 for

302 ANOVA table), indicating that the rate of species additions or losses at regional and local scales was similar among regions and succession and was not a confounding factor in

304 betadiversity analyses below. It also suggests that changes in species richness (gains and losses) at smaller and larger spatial scales through succession are not dissociated.

When using the Jaccard's metric (which does not account for variation in $\alpha$ ), variation in

$308 \beta$-diversity among disturbance timings (mean dissimilarity among quadrats disturbed at different times of the year) differed significantly among successional stages (time

310 after clearance) and consistently among regions (no interaction) (Table 1). Overall, variation in $\beta$-diversity among disturbance timings tended to decrease with succession,

312 i.e. assemblages disturbed at different times of the year became increasing similar with time (Fig. 3). When using the Bray-Curtis' metric (which does not account for variation

314 in $\alpha$, but includes abundance data), there was a significant interaction between Region and Successional Month (Table 1). Inspection of pair-wise comparisons (not shown)

316 and Figure 3 showed that the response of $\beta$-diversity (dissimilarity among disturbance timings) to succession was variable and specific for each region, when accounting for

318 species relative abundances. In other words, timing of disturbance not only influenced the identities of species, but also their abundances during community recovery, but the response was highly variable among regions.

322 When using the modified Raup-Crick metric (which accounts for variation in $\alpha$ ), variation in $\beta$-diversity among disturbance timings was significant among successional 
variation among regions (Table 1). More importantly, inspection of Figure 3 shows that

326 the metric was similar to zero $(-0.07 \pm 0.07$, mean $\pm S E$, pooling among the three regions) during the early stages of succession, but that it gradually deviated from zero as succession proceeded. It averaged $-0.40 \pm 0.07$ twelve months post disturbance, a value that was similar to that of controls with $-0.53 \pm 0.06$. This indicates that disturbed communities assembling at different times of the year were initially very variable, but progressively became more similar than expected by chance (compared to the null 332 model), as succession proceeded.

334 Partitioning species turnover into its compositional (SER $\mathrm{R}_{\mathrm{r}}$ ) and abundance (SERa) components showed that the process of community assembly through succession was

336 mostly the result of species replacements (mean SER $=0.64$, mean SERa $=0.14$ )(Fig. 4). For nine and twelve month old assemblages, however, species turnover was not only the result of species replacements (mean $S E R_{r}=0.60$ ), but there were also substantial changes in species abundances (mean SERa $=0.37$ ) (Fig. 4). SERr and SERa varied significantly with timing of disturbance clearance and successional stage at the scale of locations, but not at regional scales (see Online Resource 3 for PERMANOVA)

\section{DISCUSSION}

344 Community succession has received considerable attention from ecologists in general, and marine ecologists in particular (see Jenkins and Martins 2010 for review). In fact,

346 the study of natural succession in marine intertidal ecosystems has contributed substantially to the development of ecological theory, such as the seminal paper of

348 Connell and Slayter (1977), where three alternative models of community succession (facilitation, tolerance and inhibition), and their relative roles for community structure 
and stability, were defined. Despite decades of research, there is still considerable controversy about whether ecological communities generally converge towards a

352 common structure or not (Fukami et al. 2005). In fact, even though assembly history can influence both the structure of communities and the functional properties of ecosystems, and thus is of both theoretical and applied interest, the factors determining the circumstances under which historical contingency can occur have received considerably less attention than other areas of community ecology (Fukami 2015).

358 Our study showed that, as predicted, there was considerable variability in the structure of assemblages disturbed at different times of the year during early stages of 360 community assembly. This finding concurs with the wider body of literature of intertidal communities stressing that during early stages of community assembly,

362 timing of disturbance can have an enormous impact on assemblage structure, because of seasonality in organisms' reproductive patterns, or due to seasonality in species'

364 growth rates in relation to temporal variation in environmental conditions (BenedettiCecchi and Cinelli 1993; Underwood and Chapman 2006; Jenkins and Martins 2010.

366 Furthermore, during these early stages of community assembly, patterns of assemblage structure did not differ from that created by random community assembly suggesting the stochastic nature of the initial stages of community assembly. This variability in the initial stages of community assembly reflected not only changes in community 370 composition (as suggested by the Jaccard dissimilarity), probably arising as a consequence of temporal differences in the composition of species available for

372 colonisation at the time when resources were freed, but also changes in species abundances (as suggested by the Bray-Curtis dissimilarity), potentially arising as a 
consequence of temporal variability in environmental conditions modifying species growth rates.

$\beta$-diversity, that is the variability in the structure of assemblages disturbed at different times of the year, tended to reduce as time since disturbance elapsed. This was evident both when considering variation in assemblage composition (Jaccard) but also species 380 abundances (Bray-Curtis). Moreover, the signal clearly deviated from that of random community assembly as succession proceeded (Raup-Crick). Our study thus suggests that stochastic processes likely prevailed during early stages of community assembly, but tended to become progressively less important as succession proceeded.

In the rocky intertidal, two situations have been shown to occur: one in which despite significant variability in recruitment regimes there is high ecological convergence in late successional communities (e.g. Caro et al. 2010), and one where priority effects lead to the development of structurally and functionally different communities (e.g. BenedettiCecchi 2000). A fundamental question is thus to understand under what circumstances

390 can priority effects determine the outcome of community assembly after a given disturbance. Fukami (2015) discussed a number of factors thought to determine the relative importance of priority effects for community assembly. These included a group of factors that influence the rate of local population dynamics (e.g. small habitat patch

394 size, high productivity, low environmental variability and low predation pressure) relative to species immigration. The rationale here is that priority effects can only occur when local population dynamics are fast, relative to species immigrations, so that early colonisers grow rapidly in biomass or population size to pre-empt or modify niches before the arrival of later-colonisers (Fukami 2015). In addition the properties of 
regional species pools (e.g. species richness, species traits) and the extent to which the species pool is decoupled from local population dynamics are proposed to be important. Fukami (2015) argues that priority effects should generally be stronger, the greater the 402 diversity and stability of the regional species pool (see Fukami 2015 for detailed discussion of these factors).

404

Our study was replicated in three distinct regions differing not only in regional species 406 pool but also in productivity. Moreover, the size of our experimentally disturbed patches was judged to be large enough to prevent the rapid monopolisation of space

408 from the adjacent community (e.g. via lateral vegetative growth) yet small enough to ensure that it could be easily monopolised by the species first arriving to the patch

410 (Martins et al. 2010). Regardless, we found no evidence of strong priority effects in any of the three regions. The impact of priority effects would have been clearly identified if 412 assemblages disturbed at different times of the year (which promoted the stochastic early stages of community assembly) had become more diverse (less similar) than

414 expected by random community assembly. However, the reverse was true with assemblages becoming progressively more similar than expected by chance with 416 succession. This result thus refutes the idea that priority effects had an important role in determining community structure in our study systems. Limited seasonal variation in 418 propagule/larvae availability could have hindered the possibility of priority effects. However, 1-month old disturbed patches, taken as a reasonable proxy for species 420 settlement and recruitment, and hence to the availability of propagules or larvae, showed significant variation in assemblage structure in terms of abundance and 422 composition disturbed at different times of the year. Our results indicate that despite early variation in community composition, there was a remarkable determinism in 
community succession across all regions. Why is it then that priority effects had little influence in our study systems?

We found that the ratio of $\gamma$-to- $\alpha$ diversity remained equivalent over succession and that

428 this was true at three distinct regions under contrasting environmental variability. That is, effects of succession were scale-invariant; reductions or increases in species

430 occurred to the same extent throughout succession at smaller and larger spatial scales. In other words, species pools were not decoupled from local dynamics. This suggests

432 that the subset of species of the regional species pool available for colonisation at any given time was not stable and that there was potentially a limited supply of immigrants

434 that could colonise patches at any given step during community assembly, in turn limiting the probability for the development of divergent assemblages (Fukami 2015).

436 Moreover, strong priority effects require that species are competitively similar. This similarity ensures (or makes possible) that the outcome of competitive interactions is 438 sensitive to the arrival of species. However, under strong competitive hierarchy, species arrival order should have little influence since the most competitive species eventually

440 dominate regardless of patch history (Fukami 2015). As suggested by the partition of species turnover into its compositional and abundance components, variation in

442 diversity along succession was mostly associated with species replacements. In other words, new species kept replacing previously 'established' species as time since

444 disturbance increased. This and the fact that species tended to converge into a similar assemblage structure with succession lends support to the idea that competitive

446 hierarchy was present in our study systems and hence supports the competitioncolonisation model of succession, which predicts that late successional species outcompete early successional species (Pacala and Rees 1998). Although we cannot 
infer mechanisms from our observational approach, we suspect that differences in

450 biological traits among species (e.g. reproductive output, seasonality in reproduction, growth rate) correlate with competitive ability and determine the colonisation-

452 competition trade-off through succession (Jenkins and Martins 2010). This is supported by the work of Viejo et al. (2008) in the NE Atlantic, who showed that different

454 mechanisms (both inhibitory and facilitative) operate throughout succession and that competition among species with different traits is important. For instance, even though

456 during early stages of colonisation early-successional species (ephemeral green algae) were able to delay the colonisation of late-successional species (canopy algae), the latter

458 eventually dominated at the end of the experiment. This, in turn, inhibited the establishment of some species, whilst facilitating the establishment of others (Viejo et 460 al. 2008).

462 It is possible that our experimental design may have hampered our ability to detect priority effects. Disturbance scale may have an important influence on the

464 establishment of divergent assemblages. Disturbance of larger areas could be more likely to remove those species involved in positive feedbacks, which maintain 466 community state. Loss of such species may allow the arrival and establishment of species of potentially alternative assemblages (e.g. Petraitis and Latham 1999).

468 Specifically, Petraitis et al. (1999) showed that in the Gulf of Maine, divergence in the structure of intertidal assemblages was unlikely in disturbed patches smaller than $2 \mathrm{~m}^{2}$.

470 In one of our study systems (Azores), Martins et al. (2010) found little effect on the outcome of succession among disturbed patches of differing size, the largest of which

472 was at least 3 times larger than the ones used here. It is possible that even these were still not large enough. However, in ecosystems with narrow tidal ranges (our insular 
systems), a disturbance larger than $3 \mathrm{~m}^{2}$ would effectively include the removal of all species from the lowest intertidal level up to the littorinid zone, high up on the shore.

476 Such a disturbed area would encompass a range of environmental conditions (as a function of shore height) and blur the interpretation of any outcome compared to that 478 of smaller patches. Moreover, this would confound the comparison between the continental (macrotidal) and insular (microtidal) ecosystems. The fact that structure of early successional assemblages assembling at distinct times of the year was very variable suggests that, at least, our plot size did not limit the colonisation of species that 482 might lead to alternative assemblages.

484 Chase and Myers (2011) also highlighted that changes in the size of the regional species pool ( $\gamma$-diversity) can lead to changes in $\beta$-diversity, as long as $\alpha$-diversity does not change at the same rate as $\gamma$-diversity. In our approach, we estimated $\beta$-diversity separately for each location and successional age. This could, in theory, impair the comparisons among regions and even among successional stages. However, the fact that changes in $\gamma$ - and $\alpha$-diversity remained unchanged through succession and were similar among regions (see Fig. 2), suggests this was not a confounding factor in our estimates of $\beta$-diversity.

In summary, we found evidence that, in diverse rocky shore ecosystems and over large 494 spatial scales, differences in the identities and abundances of species that are available to colonise disturbed patches at any given time, although relatively important during early stages of community assembly, had little to no effect on the longer-term structure of intertidal assemblages. Furthermore, we found little support for strong priority effects despite changes in species pools, productivity and environmental conditions 
among the three regions. Instead, there was strong determinism in the process of community assembly suggesting that environmental filtering or strong interactions among a subset of species can shape assemblages into a relatively convergent structure.

502

\section{Acknowledgments}

504 Funding was provided from National Funds through FCT - Fundação para a Ciência e a Tecnologia, under the project UID/BIA/00329/2013. GMM was supported by post506 doctoral grants awarded also by FCT (SFRH/BDP/63040/2009 and SFRH/BDP/108114/2015). Sampling at the Canary Islands was funded by the Spanish 508 MINECO ‘Plan Nacional' (ANTROTIDAL, CGL 2011-23833).

\section{REFERENCES}

Adler PB, HilleRisLambers J, Levine JM (2007) A niche for neutrality. Ecol Lett 10:95104.

Airoldi L (2003) Effects of patch shape in intertidal algal mosaics: roles of area, perimeter and distance from edge. Mar Biol 143:639-650.

Alonso D, Etienne RS, McKane AJ (2006) The merits of neutral theory. Trends Ecol Evol 21:451-457.

Anderson MJ (2001) A new method for non-parametric multivariate analysis of variance. Aust Ecol 26:32-46.

Anderson MJ, Crist TO, Chase JM, Vellend M, Inouye BD, Freestone AL, Sanders NJ, Cornell HV, Comita LS, Davies KF, Harrison SP, Kraft NJB, Stegen JC, Swenson NG (2011) Navigating the multiple meanings of $\beta$-diversity: a roadmap for the practicing ecologist. Ecol Lett 14:19-28. 
Anderson MJ, Tolimieri N, Millar RB (2013) Beta diversity of demersal fish assemblages in the North-Eastern Pacific: Interactions of latitude and depth. PLoS ONE 8(3):e57918.

526 Araújo R, Bárbara I, Tibaldo M, Bereciber E, Tapia PD, Pereira R, Santos R, Pinto IS (2009) Checklist of benthic marine algae and cyanobacteria of northern Portugal. Bot Mar 52:24-46.

Benedetti-Cecchi L (2000) Priority effects, taxonomic resolution, and the prediction of variable patterns of colonisation of algae in littoral rock pools. Oecologia 123:265-274.

532 Benedetti-Cecchi L, Cinelli F (1993) Early patterns of algal succession in a mid-littoral community of the Mediterranean Sea: a multifactorial experiment. J Exp Mar Biol Ecol 169:15-31.

Berlow EL (1997) From canalization to contingency: historical effects in a successional rocky intertidal community. Ecol Monogr 67: 435-460.

Breitburg DL (1985) Development of a subtidal epibenthic community - factors affecting species composition and the mechanisms of succession. Oecologia 65:173-184.

540 Caro AU, Navarrete SA, Castilla JC (2010) Ecological convergence in a rocky intertidal shore despite high spatial variability in recruitment regimes. Proc Natl Acad Sci USA 107:18528-18532.

Chase JM (2007) Drought mediates the importance of stochastic community assembly. Proc Natl Acad Sci USA 104:17430-17434.

Chase JM (2010) Stochastic community assembly causes higher biodiversity in more productive environments. Science 328:1388-1391. 
Chase JM (2014) Spatial scale resolves the niche versus neutral theory debate. J Veg Sci $25: 319-322$.

Chase JM, Myers JA (2011) Disentangling the importance of ecological niches from stochastic processes across scales. Philos Trans R Soc Lond B Biol Sci 366:23512363.

552 Chase JM, Biro EG, Ryberg WA, Smith KG (2009) Predators temper the relative importance of stochastic processes in the assembly of prey communities. Ecol Lett 12:1210-1218.

Chase JM, Kraft JB, Smith KG, Vellend M, Inouye BD (2011) Using null models to disentangle variation in community dissimilarity from variation in $\alpha$-diversity. Ecosphere 2:1-11.

558 Clarke, KR, Gorley RN (2006) PRIMER v6: User Manual/Tutorial. PRIMER-E, Plymouth, 192pp.

560 Connell JH, Slayter RO (1977) Mechanisms of succession on natural communities and their role in community stability and organization. Am Nat 111:1119-1144.

562 Dayton PK, Currie V, Gerrodette T, Keller BD, Rosenthal R, Ven Tresca D (1984) Dynamics and stability of some California kelp communities. Ecol Monogr 54:254-289.

Dethier MN, Graham ES, Cohen S, Tear LM (1993) Visual versus random-point percent cover estimations: 'objec- tive' is not always better. Mar Ecol Prog Ser 96:93-100.

Dornelas M, Connolly SR, Hughes TP (2006) Coral reef diversity refutes the neutral 568 theory of biodiversity. Nature 440:80-82.

Ellingsen KE, Gray JS (2002) Spatial patterns of benthic diversity: is there a latitudinal gradient along the Norwegian continental shelf? J Anim Ecol 71:373-389. 
Fukami T (2015) Historical contingency in community assembly: Integrating niches, species pools, and priority effects. Annu Rev Ecol Evol S 46:1-23.

Fukami T, Bezemer TM, Mortimer SR, van der Putten WH (2005) Species divergence and trait convergence in experimental plant community assembly. Ecol Lett 8:1283-1290.

576 Garzon-Lopez CX, Jansen PA, Bohlman SA, Ordonez A, Olff H (2014) Effects of sampling scale on patterns of habitat association in tropical trees. J Veg Sci 25:349-362.

578 Gravel D, Canham CD, Beaudet M, Messier C. 2006. Reconciling niche and neutrality: the continuum hypothesis. Ecol Lett 9:399-409.

580 Hawkins SJ, Corte-Real HBSM, Pannacciulli FG, Weber LC (2000) Thoughts on the ecology and evolution of the intertidal biota of the Azores and other Atlantic islands. Hydrobiologia 440:3-17.

Hernández-Léon S (1988) Gradients of mesozooplankton biomass and ETS activity in the wind-shear area as evidence of an island mass effect in the Canary Island waters. J Plankton Res 10:1141-1154.

586 Hillebrand H, Blasius B, Borer ET, Chase JM, Downing JA, Eriksson BK, Filstrup CT, Harpole WS, Hodapp D, Larsen S, Lewandowska AM, Seabloom EW, Van de Waal DB, Ryabov AB (in press) Biodiversity change is uncoupled from species richness trends: consequences for conservation and monitoring. J Appl Ecol.

590 Hubbell SP (2001) The unified neutral theory of biodiversity and biogeography. Princeton Univ Press, New Jersey.

592 Jenkins SR, Coleman RA, Della Santina P, Hawkins SJ, Burrows MT, Hartnoll RG (2005) Regional scale differences in the determinism of grazing effects in the rocky intertidal. Mar Ecol Prog Ser 287:77-86. 
Jenkins SR, Marshall D, Fraschetti S (2009) Settlement and recruitment. In: Wahl M (ed) Marine hard bottom communities: Patterns, dynamics, diversity and change. Springer, Berlin, pp 177-190.

598 Jenkins SR, Martins GM (2010) Succession on hard substrata. In: Dürr S, Thomason JC (eds) Biofouling. Wiley-Blackwell, Oxford, pp 60-72.

600 Lima F, Ribeiro PA, Queiroz N, Hawkins SJ, Santos A (2007) Do distributional shifts of northern and southern species of algae match the warming pattern? Glob Change Biol 13:2592-2604

Martins AM, Amorim ASB, Figueiredo MP, Sousa RJ, Mendonça AP, Bashmachnikov IL, 604 Carvalho DS (2007) Sea surface temperature (AVHRR, MODIS) and ocean colour (MODIS) seasonal and interannual variability in the Macaronesian islands of

Martins GM, Jenkins SR, Ramírez R, Tuya F, Neto AI, Arenas F (2014) Early patterns of Azores, Madeira, and Canaries. Proc SPIE 6743: 67430A-1.

Martins GM, Thompson RC, Neto AI, Hawkins SJ, Jenkins SR (2010) Exploitation of intertidal grazers as a driver of community divergence. J Appl Ecol 47:12821289.

Martins GM, Prestes ACL, Neto AI (2013) Effects of density versus size on grazing by a 614 key exploited herbivore. Vie et Milieu 64:35-40.

Navarrete SA, Wieters E, Broitman B, Castilla JC (2005) Scales of benthic-pelagic 616 coupling and the intensity of species interactions: from recruitment limitation to top down control. Proc Natl Acad Sci USA 102:18046-18051.

618 Norton TA (1992) Dispersal by macroalgae. British Phycol J 27:293-301. 
Pacala SW, Rees M (1998) Models suggesting field experiments to test two hypothesis explaining successional diversity. Am Nat 152:729-737.

Petraitis PS, Latham RE (1999) The importance of scale in testing the origins of alternative community states. Ecology 80:429-442.

Petraitis PS, Methratta ET, Rhile EC, Vidargas NA, Dudgeon SR (1999) Experimental 624 confirmation of multiple community states in a marine ecosystem. Oecologia 161:139-148.

626 Raup D, Crick RE (1979) Measurement of faunal similarity in paleontology. J Paleontol $53: 1213-1227$.

628 Santos F, Gómez-Gesteira M, deCastro M, Álvarez I (2011) Upwelling along the western coast of the Iberian Peninsula: dependence of trends on fitting strategy. Clim Res 48:213-218.

Smith KG, Lips KR, Chase JM (2009) Selecting for extinction: nonrandom diseaseassociated extinction homogenizes amphibian biotas. Ecol Lett 12:1069-1078.

Sousa WP (1985) Disturbance and patch dynamics on rocky intertidal shores. In: Pickett 634 STA, White PS (eds) The ecology of natural disturbance and patch dynamics. Academic Press, Orlando, pp, 101-124.

Stegen JC, Freestone AL, Crist TO, Anderson MJ, Chase JM, et al. (2012) Stochastic and deterministic drivers of spatial and temporal turnover in breeding bird communities. Global Ecol Biogeogr 22:202-212.

Tucker CM, Shoemaker LG, Davies KF, Nemergut DR, Melbourne BA (2016) Differentiating between niche and neutral assembly in metacommunities using null models of $\beta$-diversity. Oikos 125:778-789. 
642 Tuya F, Cacabelos E, Duarte P, Jacinto D and others (2012) Patterns of landscape and assemblage structure along a latitudinal gradient in ocean climate. Mar Ecol Prog

644 Ser 466:9-19.

Tuya F, Haroun RJ (2009) Phytogeography of Lusitanian Macaronesia: biogeographic 646 affinities in species richness and assemblage composition. Eur J Phycol 44:405413.

648 Underwood AJ, Chapman MG (2006) Early development of subtidal macrofaunal assemblages: relationships to period and timing of colonization. J Exp Mar Ecol Biol 330:221-233.

Vadas RL, Johnson S, Norton TA (1992) Recruitment and mortality of early postsettlement stages of benthic algae. Br Phycol J 27:331-351.

Vellend M, Srivastava DS, Anderson KM, Brown CD, Jankowski JE, Kleynhans EJ, Kraft 654 NJB, Letaw AD, Macdonald AAM, Maclean JE, Myers-Smith IH, Norris AR, Xue X (2014) Assessing the relative importance of neutral stochasticity in ecological communities. Oikos 123:1420-1430.

Viejo R, Arenas F, Fernández C, Gómez M (2008) Mechanisms of succession along the 658 emersion gradient in intertidal rocky shore assemblages. Oikos 117:376-389.

Whittaker R (1960) Vegetation of the Siskiyou mountains, Oregon and California. Ecol 660 Monogr 30:279-338.

Whittaker R (1972) Evolution and measurement of species diversity. Taxon 21:213662 251.

Wootton JT (2005) Field parameterization and experimental test of the neutral theory of biodiversity. Nature 433:309-312. 
Table 1. Two-way permutational ANOVA testing the effects of disturbance timing on community dissimilarities among three regions (Northern Portugal, Azores and Canaries) throughout succession (time after clearance). ${ }^{*} \mathrm{P}<0.05,{ }^{* *} \mathrm{P}<$ $0.01,{ }^{* * *} \mathrm{P}<0.001$

\begin{tabular}{lcccccccc}
\hline & \multicolumn{4}{c}{ Jaccard } & \multicolumn{2}{c}{ Bray-Curtis } & \multicolumn{2}{c}{ Raup-Crick } \\
\hline Source & $\mathrm{df}$ & MS & $F$ & MS & $F$ & MS & $F$ \\
Region = R & 2 & 928.07 & $28.59^{* * *}$ & 2380.40 & $15.08^{* * *}$ & 0.253 & $7.03^{* *}$ \\
Suc. Month = SM & 5 & 179.41 & $4.91^{*}$ & 106.71 & 0.28 & 0.250 & $6.15^{* *}$ \\
R $\times$ SM & 10 & 36.54 & 1.13 & 380.42 & $2.41^{*}$ & 0.041 & 1.13 \\
Residual & 36 & 32.46 & & 157.82 & & 0.036 & \\
& & & & & & & &
\end{tabular}




\section{Figure captions}

Fig 1. CAP ordination of samples based on the $4^{\text {th }}$-root transformed Bray-Curtis dissimilarity. Different symbols stand for the different times of clearance, whilst the colour gradient (shades of grey) stands for successional month, from 1 month (black) through controls (white). For clarity, data are the centroids for each location

Fig. 2. Mean $( \pm S E) \gamma$-to- $\alpha$ diversity ratio through succession at each region (black: Northern Portugal, grey: Azores, white: Canary Islands)

Fig. 3. Mean $( \pm$ SE) dissimilarities among intertidal communities experimentally disturbed at different times of the year. Comparisons at different stages of succession at each of three regions (black: Northern Portugal, grey: Azores, white: Canary Islands)

Fig. 4. Bivariate plots between richness-based and abundance-based species exchange ratio (SERr and SERa) for each quadrat at successive successional stages. Different shades of grey represent different successional stages 

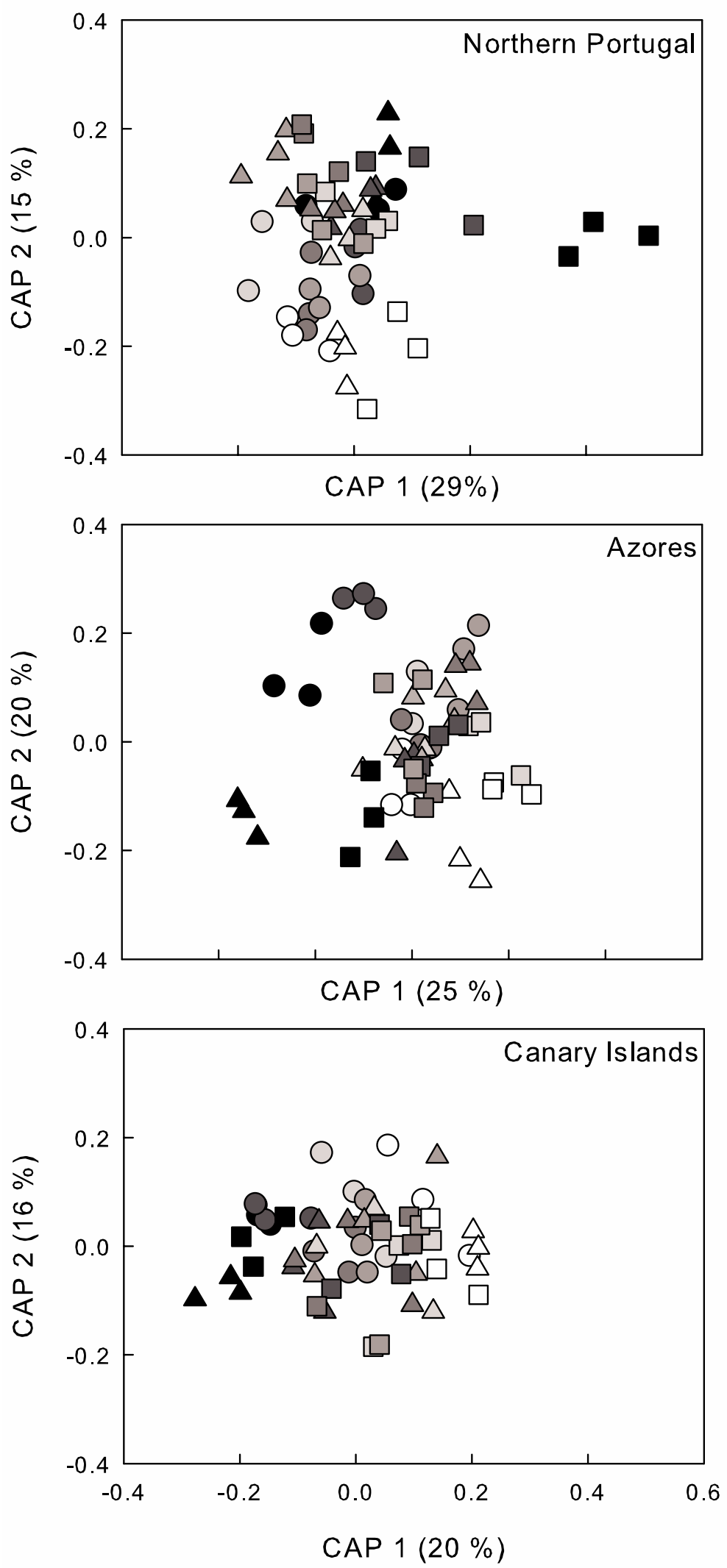

Figure 1 


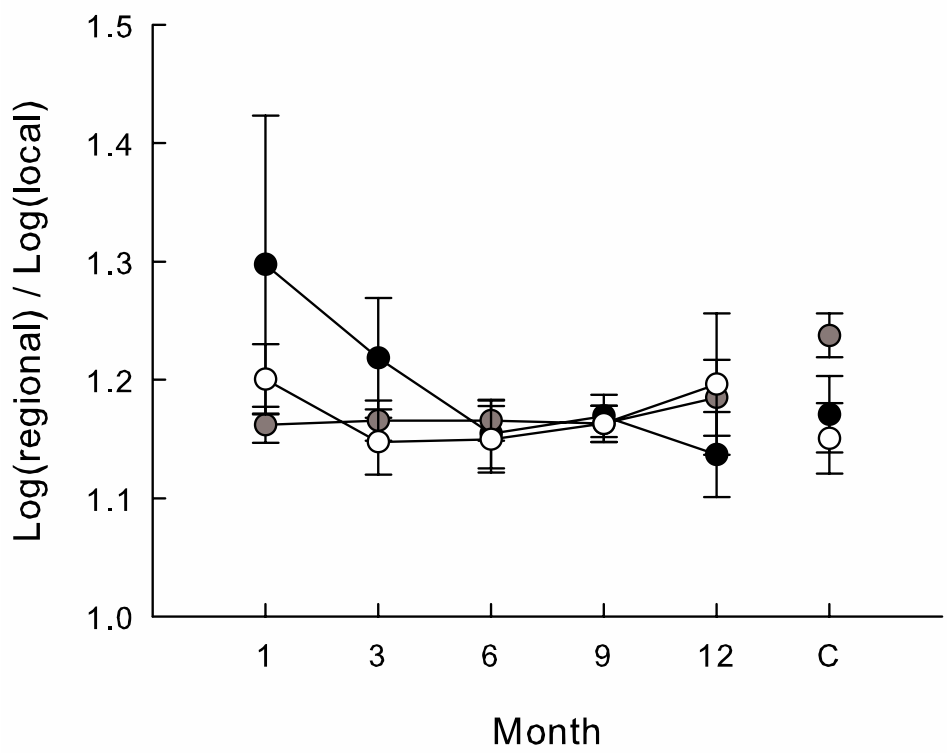

Figure 2 

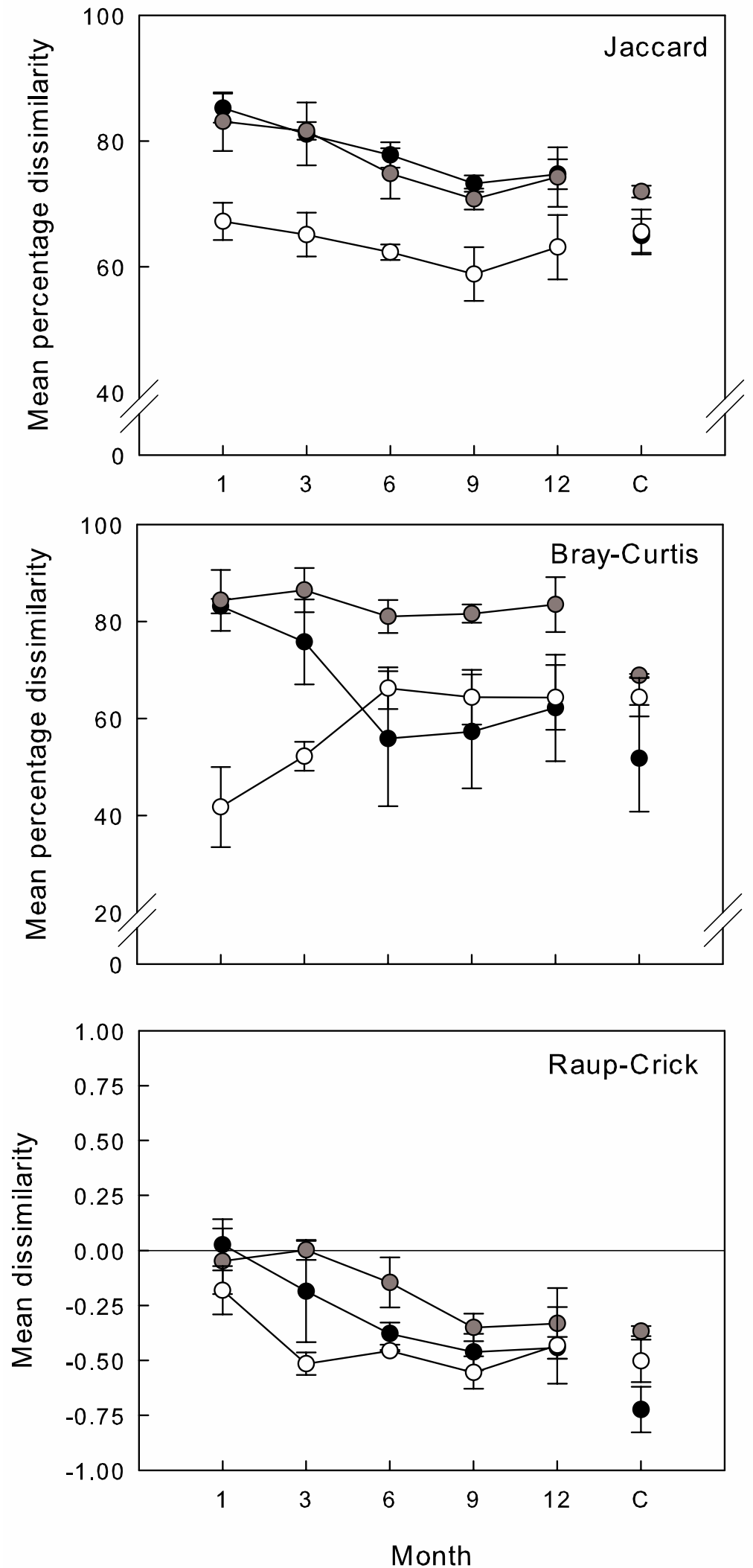

Figure 3 


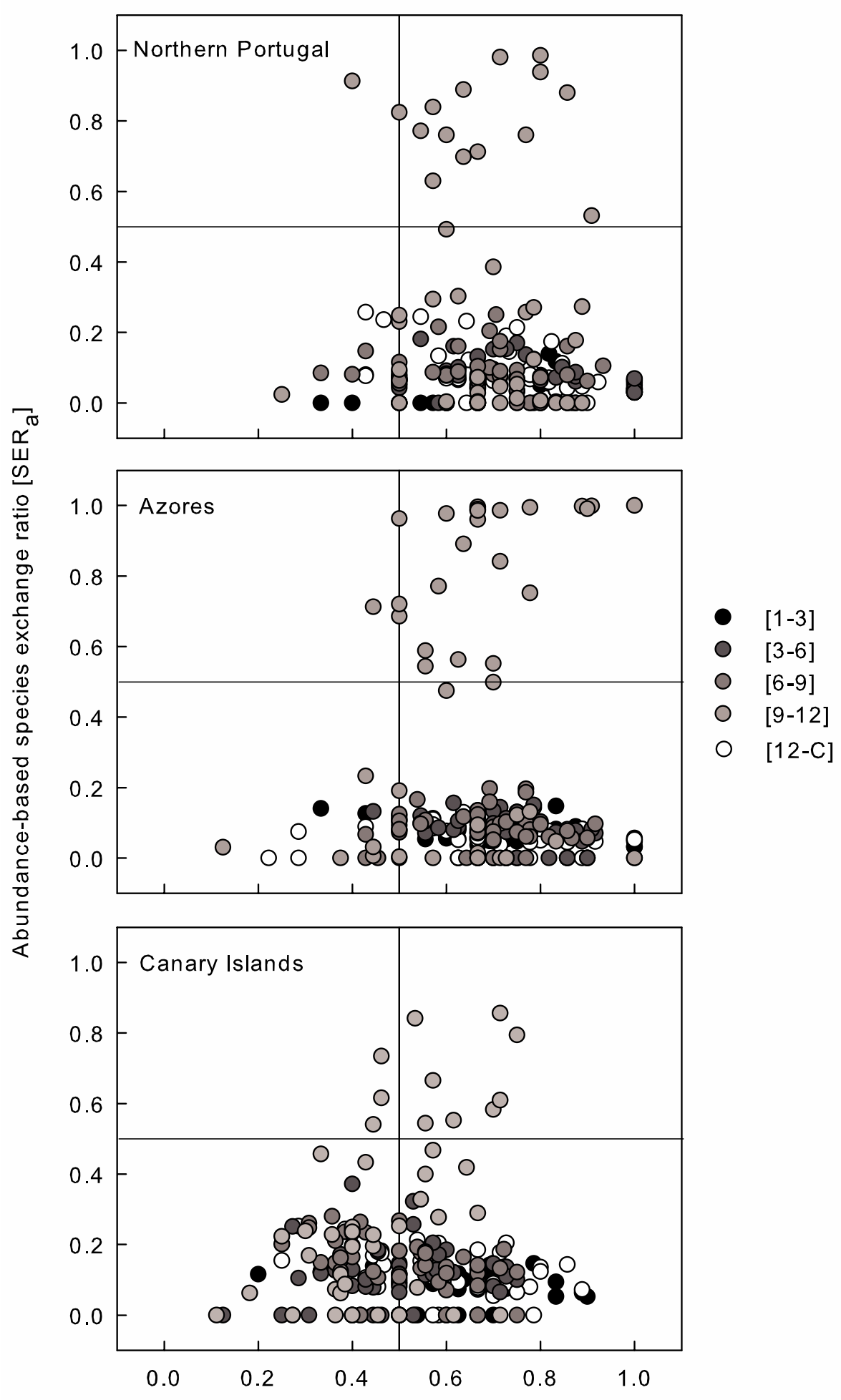

Richness-based species exchange ratio $\left[S E R_{r}\right.$ ]

Figure 4 